\title{
Occurrence, bioaccumulation and long-range transport of short-chain chlorinated paraffins on the Fildes Peninsula at King George Island, Antarctica
}

\author{
Huijuan Li, Jianjie Fu*, Aiqian Zhang *, Qinghua Zhang, Yawei Wang \\ State Key Laboratory of Environmental Chemistry and Ecotoxicology, Research Center for Eco-Environmental Sciences, Chinese Academy of Sciences, Beijing 100085, China
}

\section{A R T I C L E I N F O}

\section{Article history:}

Received 24 September 2015

Received in revised form 12 April 2016

Accepted 4 May 2016

Available online 21 July 2016

\section{Keywords:}

Short-chain chlorinated paraffins (SCCPs)

Antarctica

Biomagnification

Long-range transport

\begin{abstract}
A B S T R A C T
As a candidate persistent organic pollutant of the Stockholm Convention, short-chain chlorinated paraffins (SCCPs) have recently received particular attention. In this study, we investigated, for the first time, the concentrations of SCCPs in biota samples collected from the Fildes Peninsula at King George Island and Ardley Island, Antarctica. The concentrations of SCCPs ranged from 3.5 to $256.6 \mathrm{ng} / \mathrm{g}$ (dry weight, dw), with a mean of $76.6 \pm 61.8 \mathrm{ng} / \mathrm{g} \mathrm{dw}$, which was lower than those detected in mid- and low-latitude regions. The long-range transport behaviour of SCCPs was confirmed by both the detection of SCCPs in Antarctic remote areas and their special congener profiles. Short carbon chain $\left(C_{10}\right)$ congeners predominated in the Antarctic samples, which accounted for $56.1 \%$ of the total SCCP contamination. Such enrichment of $C_{10}$ congeners indicated the high potential for the long-range transport of shorter chain congeners. In addition, SCCPs tended to be enriched in the species with high lipid contents. The biomagnification potential of SCCPs was found between Archeogastropoda (Agas) and Neogastropoda (Ngas), and the biomagnification factors of shorter chain congeners of SCCPs were higher than that of the longer chain ones. Considering that the endemic species in polar regions may be sensitive and vulnerable to the adverse effects of environmental contaminants, more attention should be paid on the bioaccumulation and toxicological risks of SCCPs in polar environments.
\end{abstract}

(c) 2016 Published by Elsevier Ltd.

\section{Introduction}

Chlorinated paraffins (CPs) have 10-30 carbon atoms and chlorine content that ranges from 30\% to $70 \%$ by weight (Bayen et al., 2006). The variety of carbon chain lengths and chlorine contents of CPs results in diverse properties and extensive applications, including lubricant additives, plasticizers in rubbers, metal-working fluids, flame retardants, paints and sealants (Campbell and McConnell, 1980). Short-chain chlorinated paraffins (SCCPs, $\mathrm{C}_{10}-\mathrm{C}_{13}$ ) can affect the liver, thyroid hormone system, and kidneys, e.g., by inducing hepatic enzymes and hyperactivity in the thyroid, which can lead to both acute and chronic toxic effects with long-term exposure (UNEP/POPS/POPRC.8/6, 2012). Because of their potential for environmental persistence (Iozza et al., 2008), toxicity (Geng et al., 2015), bioaccumulation (Fisk et al., 1996; Houde et al., 2008; Ma et al., 2014b; Zeng et al., 2011b) and long-range atmospheric transport (Ma et al., 2014c; Vulykh et al., 2007), SCCPs have received widespread public attention. SCCPs were even included in Annex E of the Stockholm Convention by the persistent organic pollutants (POPs) Review Committee as a POP candidate in 2008 (UNEP/POPS/POPRC.3/ 20,2008 ) since these properties are quite similar to those of legacy

\footnotetext{
* Corresponding authors at: Research Center for Eco-Environmental Sciences, Chinese Academy of Sciences, Beijing 100085, China.

E-mail addresses: jjfu@rcees.ac.cn (J. Fu), aqzhang@rcees.ac.cn (A. Zhang).
}

POPs (Poremski et al., 2001). However, with the scarcity of current monitoring data, including for the occurrence, capacity for accumulation, and long-range transport, the listing of SCCPs as POPs into the Stockholm Convention remains controversial (Wang et al., 2013).

SCCPs are primarily released into the environment from anthropogenic sources as a type of high production volume chemical and are detected in the different environmental matrices, including air, water, sediments and biota (Barber et al., 2005; Bayen et al., 2006; Coelhan, 2010; Fridén et al., 2011; Marvin et al., 2003; Thomas et al., 2006; Zeng et al., 2015). The SCCPs travel to polar regions in a three-step process: release, transport and deposition (Wania, 2003). The vapour pressure of SCCPs is very low and varies from $2.8 \times 10^{-7}$ to $0.066 \mathrm{~Pa}$ (Feo et al., 2009), which make them easily volatilize into the atmosphere. Most pollutants migrate to higher latitudes in a series of relatively short jumps called the "grasshopper effect" (Wania and Mackay, 1996). SCCPs can also be transported through the atmosphere and ultimately deposited in remote areas such as the polar regions (Wania, 2003; Wania and Mackay, 1993). The detection of SCCPs in the polar regions would provide direct evidence for their long-range transport, but SCCPs have been observed in polar regions in only a few studies. The concentrations of SCCPs were studied in the biota and sediment samples from Arctic and sub-Arctic environments (Reth et al., 2006; Strid et al., 2013; Tomy et al., 2000; Tomy et al., 1999). For Antarctica, the only data for SCCPs are from the air samples collected on the Fildes Peninsula (Ma et al., 2014c). 
Antarctica is far from industrial regions and is less affected by global anthropogenic activities. Most species found in Antarctica are endemics and may be more sensitive and vulnerable to the adverse effects of persistent contaminants than those of the industrialized regions. Low levels of pollutants can have significant effects on local fragile ecosystems (Bargagli, 2008). Moreover, biomagnification through food chains can lead to relatively high contaminant concentrations in biota, which potentially threaten the health of wildlife at higher trophic levels. In several studies, SCCPs biomagnified through the food web in aquatic ecosystems (Ma et al., 2014b; Zeng et al., 2011b). As an additional factor, the temperature in Antarctica is lower than that in other regions, and based on previous studies, low temperatures may decrease the growth rate more than the uptake rate, which results in a net accumulation of POPs in the tissues of biota (Honkanen and Kukkonen, 2006; Muijs and Jonker, 2009). Therefore, relatively high levels of bioaccumulation are expected for Antarctic species.

In this study, we systematically collected soil, vegetation, and animal samples on the Fildes Peninsula at King George Island and Ardley Island, Antarctica. The primary purpose was to investigate the occurrence and congener profiles of SCCPs in Antarctic samples to demonstrate the long-range transport behaviour of SCCPs. The spatial distribution of SCCPs was also examined to determine the effect of human activities on the local Antarctic environment. Finally, the bioaccumulation behaviour of SCCPs was investigated to study the effects on the Antarctic ecosystem. The results of our study will provide valuable information on the environmental behaviour of SCCPs on a global scale.

\section{Materials and methods}

\subsection{Sampling}

The samples were all collected during the 29th Chinese Antarctic Expedition between December 2012 and January 2013. Eight soil, six algae (Halymenia floresia), six moss (Sanionia uncinata), three fish (Notothenia coriiceps), five neogastropoda (Trophon geversianus, Ngas) and sixteen archeogastropoda samples (Nacella concinna, Agas) were collected on the Fildes Peninsula at King George Island and Ardley Island, Antarctica (Fig. 1). The samples were immediately freeze-dried and homogenized at the Chinese Great Wall Station and were then transported to the laboratory in Beijing, China, and preserved at $-20^{\circ} \mathrm{C}$ in a specialized refrigerator for polar samples until analyses. Detailed information on sampling and transportation is in the Supplementary Data.

Of the sampled species, the species of Agas was the most widely distributed on the Fildes Peninsula and therefore was the sentinel species used to investigate the spatial distribution of SCCPs. Moreover, the predator-prey relationship was confirmed for Agas and Ngas (Ngas preys on Agas; Fig. S1), and therefore, paired samples of Agas and Ngas were collected from sites 5, 7, 9, 12 and 18 (Fig. 1) to study the biomagnification behaviour of SCCPs.

\subsection{Analytical procedures}

Approximately $5 \mathrm{~g}$ of soil and $2 \mathrm{~g}$ of biological samples were spiked with surrogate standards (1 ng of ${ }^{13} \mathrm{C}_{10}$-trans-chlordane), mixed with $15 \mathrm{~g}$ of anhydrous sodium sulphate and extracted with dichloromethane and hexane $(1: 1, v / v)$ using accelerated solvent extraction (Dionex ASE 350). The extract was cleaned by a multilayer Silica-Florisil column that contained $3 \mathrm{~g}$ of Florisil, $2 \mathrm{~g}$ of activated silica gel, $5 \mathrm{~g}$ of acid silica gel $(30 \%, w / w)$ and $4 \mathrm{~g}$ of anhydrous sodium sulphate from the bottom to the top. The cleanup procedure for the SCCPs was based on our previously reported methods (Zeng et al., 2011a).

The SCCPs were analysed on a 7890A high-resolution gas chromatograph (HRGC) in electron capture negative ion (ECNI) mode coupled with a 7000B triple quadruple mass spectrometer in single quad mode (Agilent, USA). $1 \mu \mathrm{L}$ of extract was injected with a 7683B Series Injector (Agilent, USA) in splitless mode into a DB-5MS capillary column (30-m length, 0.25-mm i.d., 0.25- $\mu \mathrm{m}$ film thickness; Agilent, CA).
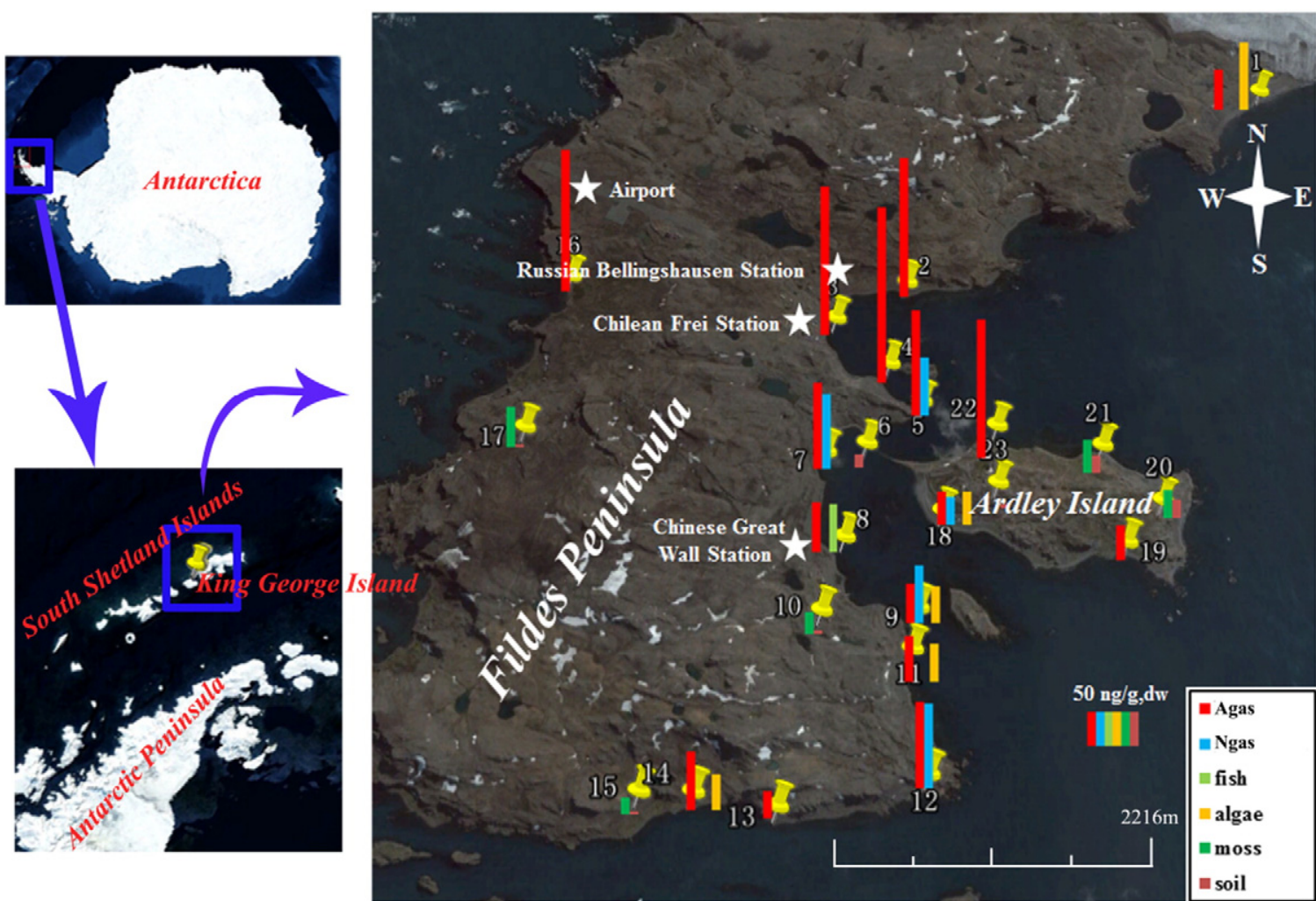

Fig. 1. Distribution of the sample sites and the concentrations of SCCPs in Antarctic samples. Numbers 1-23 are the different locations; detailed information is provided in Table S1. 
To ensure the validity of analytical identifications and quantifications, strict quality assurance and control measures were employed. The concentrations of SCCPs detected in anhydrous sodium sulphate (blank controls throughout the treatment process) were $0.67-1.27 \mathrm{ng} / \mathrm{g}$, which was $<5 \%$ of sample concentrations. The recovery of ${ }^{13} \mathrm{C}_{10}$-trans-chlordane was between $76 \%$ and $102 \%$. The recoveries for the three SCCP references with chlorine contents of $51.5 \%, 55.5 \%$, and $63.0 \%$ were between $81 \%$ and $116 \%$. Detailed information for materials and methods is provided in the Supplementary Data.

\subsection{Total organic carbon and stable nitrogen/carbon isotope analyses}

To directly compare the concentrations of SCCPs in contaminated soils from different studies, total organic carbon (TOC) in the individual soil samples was measured to normalize the concentrations of SCCPs. TOC in soil samples was measured using an O.I. Analytical Solids TOC Analyser (O.I. Analytical, USA). Before the TOC was measured, samples of approximately $0.1 \mathrm{~g}$ were treated with phosphoric acid $\left(1.0 \mathrm{~mol} \cdot \mathrm{L}^{-1}\right)$ to remove inorganic carbon.

Stable nitrogen and carbon isotope analyses $\left({ }^{15} \mathrm{~N} /{ }^{14} \mathrm{~N}_{\text {sample }}\right.$ and ${ }^{13} \mathrm{C} /{ }^{12} \mathrm{C}_{\text {sample }}$ ) were performed on $1-2 \mathrm{mg}$ of the homogenized biota samples using a Thermo DELTA V ADVANTAGE isotope ratio mass spectrometer interfaced with a Flash EA1112 HT elemental analyser (Thermo Fisher, Waltham, MA). Atmospheric nitrogen and PDB (Pee Dee Belemnite) were used as isotope ratio standards for $\mathrm{N}$ and $\mathrm{C}$, respectively. Stable isotope abundances were expressed in parts per thousand (\%) according to the following equations:

$\delta{ }^{15} \mathrm{~N}=\left[\left({ }^{15} \mathrm{~N} /{ }^{14} \mathrm{~N}_{\text {sample }} /{ }^{15} \mathrm{~N} /{ }^{14} \mathrm{~N}_{\text {standard }}\right)-1\right] \times 1000$

$\delta^{13} \mathrm{C}=\left[\left({ }^{13} \mathrm{C} /{ }^{12} \mathrm{C}_{\text {sample }} /{ }^{13} \mathrm{C} /{ }^{12} \mathrm{C}_{\text {standard }}\right)-1\right] \times 1000$.

The analytical precision for $\delta^{15} \mathrm{~N}$ was $\pm 0.2 \%$, and the analytical precision for $\delta^{13} \mathrm{C}$ was $\pm 0.1 \%$.

\subsection{Trophic levels (TLs) and biomagnification factors (BMFs)}

Trophic levels (TLs) in biota samples were determined using the following equation (Hodum and Hobson, 2000):

$\mathrm{TL}=2.3+\left(\delta^{15} \mathrm{~N}_{\text {consumer }}-\delta^{15} \mathrm{~N}_{\text {Antarctic krill }}\right) / 3.3$.
Biomagnification factors (BMFs) of the SCCPs between Agas and Ngas were calculated according to the following equation (Fisk et al., 2001):

$\mathrm{BMF}=[$ predator $] /[$ prey $] /(\mathrm{TL}$ predator $/ \mathrm{TL}$ prey $)$

where [predator] and [prey] are the lipid-normalized concentrations of SCCPs in Ngas and Agas samples, respectively.

\subsection{Statistical analyses}

Statistical analyses were performed using IBM SPSS Statistics Version 20 for Windows. The level of statistical significance was defined at $p<0.05$. Mean concentrations and standard deviation for each species are listed in Table 1, after testing the normality of the data by OneSample Kolmogorov-Smirnov Test. Difference in concentrations among species and locations was detected using one-way ANOVA with Student's $t$-test. Correlation analysis was conducted based on the calculation of Pearson's correlation coefficients between the tested variables. The regression analysis was only used for the variables found to be significant correlated to explore their quantitative relationship. Specifically, Pearson's correlation coefficients were calculated between SCCPs concentrations in organisms and lipid contents of the species as well as lipid-normalized concentrations of SCCPs and trophic levels. Linear regression analysis was then performed to explore the influence of the lipid contents on the SCCPs concentrations. The results for the statistical analyses were described in the Supplementary Data.

\section{Results and discussion}

\subsection{SCCP concentrations}

SCCPs were detected in all samples (Table S2), and detailed information for each species is listed in Table 1 . To our knowledge, this is the first report of SCCPs concentrations in Antarctic biota samples. The occurrence of SCCPs in the different Antarctic matrices indicated that this type of organic pollutant was sufficiently persistent to travel from industrialized regions to polar regions. In the animal samples, the concentrations of SCCPs ranged from 40.2 to $256.6 \mathrm{ng} / \mathrm{g}$ dry weight (dw). In the vegetation samples, the concentrations of SCCPs ranged from 24.9 to $97.7 \mathrm{ng} / \mathrm{g} \mathrm{dw}$. For the contamination of soils, the range of SCCP concentrations was $3.5-32.8 \mathrm{ng} / \mathrm{g} \mathrm{dw}$. The concentrations of SCCPs in the animal samples were higher than those in the vegetation samples, and the lowest concentrations were found in the soil samples. Thus,

Table 1

Detailed parameters and concentrations of SCCPs in multiple matrices from the Antarctic.

\begin{tabular}{|c|c|c|c|c|c|c|c|c|}
\hline Species & $n$ & $\delta^{13} \mathrm{C}(\%)$ & $\delta^{15} \mathrm{~N}(\% \circ)$ & Lipid content (\%) & TOC (\%) & $\begin{array}{l}\Sigma S C C P s \\
(n g / g d w)\end{array}$ & $\begin{array}{l}\sum \text { SCCPs } \\
(\mathrm{ng} / \mathrm{g} w w)\end{array}$ & $\begin{array}{l}\Sigma S C C P S \\
(\mu \mathrm{g} / \mathrm{g} \mathrm{lw})\end{array}$ \\
\hline \multicolumn{9}{|l|}{ Animal samples } \\
\hline $\begin{array}{l}\text { Archeogastropoda } \\
\text { (Nacella concinna) }\end{array}$ & 16 & $-14.9 \pm 1.3^{\mathrm{a}}$ & $5.6 \pm 0.5$ & $8.5 \pm 1.3$ & N.T. ${ }^{b}$ & $123.6 \pm 73.3$ & $24.6 \pm 14.6$ & $1.5 \pm 1.0$ \\
\hline Neogastropoda (Trophon geversianus) & 5 & $-16.0 \pm 0.8$ & $7.9 \pm 0.3$ & $4.8 \pm 3.3$ & N.T. & $88.9 \pm 31.7$ & $20.4 \pm 7.3$ & $2.7 \pm 2.1$ \\
\hline $\begin{array}{l}\text { Fish } \\
\text { (Notothenia coriiceps) } \\
\text { Vegetation samples }\end{array}$ & 3 & $-18.1 \pm 1.6$ & $11.5 \pm 0.2$ & $5.7 \pm 3.6$ & N.T. & $69.9 \pm 13.5$ & $16.8 \pm 3.2$ & $1.5 \pm 0.5$ \\
\hline $\begin{array}{l}\text { Algae } \\
\text { (Halymenia floresia) }\end{array}$ & 6 & $-19.6 \pm 2.9$ & $-2.4 \pm 9.3$ & $3.4 \pm 2.1$ & N.T. & $61.3 \pm 18.3$ & $9.6 \pm 2.9$ & $2.8 \pm 2.0$ \\
\hline $\begin{array}{l}\text { Moss } \\
\text { (Sanionia uncinata) } \\
\text { Abiotic samples }\end{array}$ & 6 & $-24.3 \pm 1.6$ & $1.8 \pm 4.0$ & $2.7 \pm 0.9$ & N.T. & $42.3 \pm 15.2$ & $8.5 \pm 3.7$ & $1.7 \pm 0.7$ \\
\hline Soil & 8 & N.T. & N.T. & N.T. & $8.8 \pm 12.2$ & $14.8 \pm 11.4$ & N.T. & $0.7 \pm 0.6^{c}$ \\
\hline
\end{tabular}

a Mean \pm standard deviation (SD).

b Normalized to total organic carbon (TOC).

c Not tested. 
the concentrations of SCCPs were higher in living organisms than those in the environmental substrate.

Based on comparisons of the SCCP concentrations with those of other studies, the concentrations of SCCPs were relatively low in the Antarctic animal samples, which were approximately one-tenth of those in mollusks from the Chinese Bohai Sea (109.6 ng/g vs. $1410 \mathrm{ng} /$ $\mathrm{g} \mathrm{dw}$, respectively) (Yuan et al., 2012). The SCCP concentrations in the Agas (24.6 ng/g wet weight, ww), Ngas (20.4 ng/g ww), and fish samples ( $16.8 \mathrm{ng} / \mathrm{g} \mathrm{ww}$ ) were lower than those in marine mammal blubber from the Canadian Arctic (210 ng/g ww) (Tomy et al., 2000); however, the range of SCCP concentrations in the Antarctic biota was similar to that in biota from the European Arctic (5-88 ng/g ww) (Reth et al., 2006). Compared with the concentrations in Antarctic vegetation samples, Wang et al. (2015) found a much higher concentration of SCCPs in vegetation from Beijing, which varies from 980 to $1090 \mathrm{ng} / \mathrm{g} \mathrm{dw}$ in bark and needle samples. The SCCP concentrations in Antarctic soil samples were lower than those detected in soils from the Liaohe River basin, China (14.8 vs. $114.7 \mathrm{ng} / \mathrm{g} \mathrm{dw}$, respectively) (Gao et al., 2012).
The concentrations of SCCPs in this study were much higher than those of other POPs in the Antarctic area. Borghini et al. (2005) reported that the concentrations of polychlorinated biphenyls (PCBs) were $0.4-0.6 \mathrm{ng} / \mathrm{g} \mathrm{dw}$ in soil and $23-34 \mathrm{ng} / \mathrm{g} \mathrm{dw}$ in moss from Victoria Land, Antarctica, which are values nearly twofold lower than the SCCP concentrations in our study. Wang et al. (2012) investigated the PCBs and the polybrominated diphenyl ethers (PBDEs) from an identical sample area, the mean concentration of PCBs was $0.4 \mathrm{ng} / \mathrm{g} \mathrm{dw}$ in soil and $0.7 \mathrm{ng} / \mathrm{g} \mathrm{dw}$ in moss, and the mean concentration of PBDEs was $0.024 \mathrm{ng} / \mathrm{g} \mathrm{dw}$ in soil and $0.016 \mathrm{ng} / \mathrm{g} \mathrm{dw}$ in moss. Compared with the SCCP concentrations in this study $(14.8 \mathrm{ng} / \mathrm{g} \mathrm{dw}$ in soil and $42.3 \mathrm{ng} / \mathrm{g}$ $\mathrm{dw}$ in moss), those concentrations are much lower. These comparisons all indicate that the SCCPs contamination is a primary component of the POP burden in Antarctica. Moreover, in regions other than Antarctica, SCCPs are also a dominant component of POP contamination; for example, in our previous studies, the concentration of SCCPs (Yuan et al., 2012) was higher than that of other POPs in samples from the Chinese Bohai Sea (Wang et al., 2008; Zhu et al., 2012). Thus, the global pollution of SCCPs requires further attention.
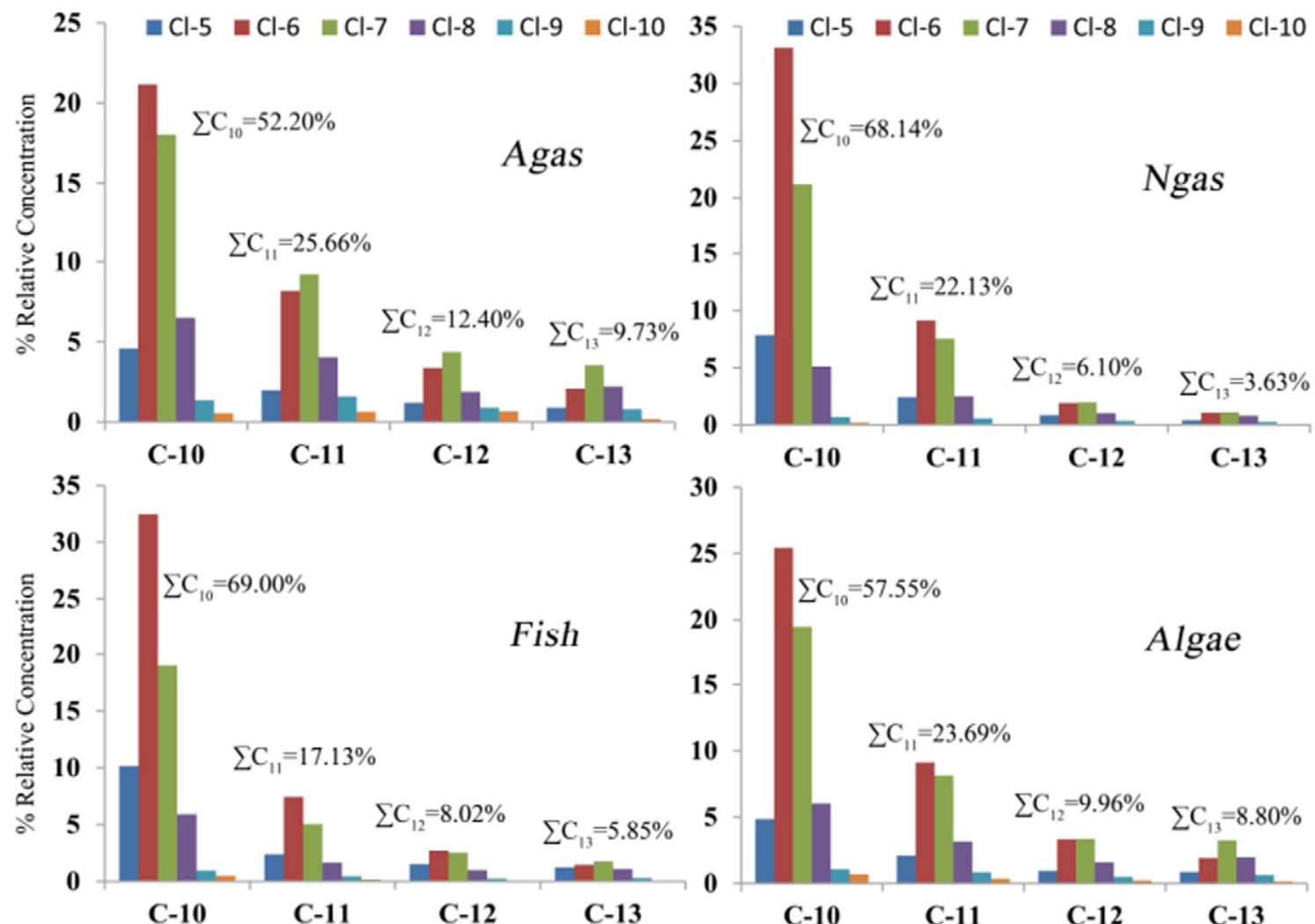

C-11

C-12

C-13
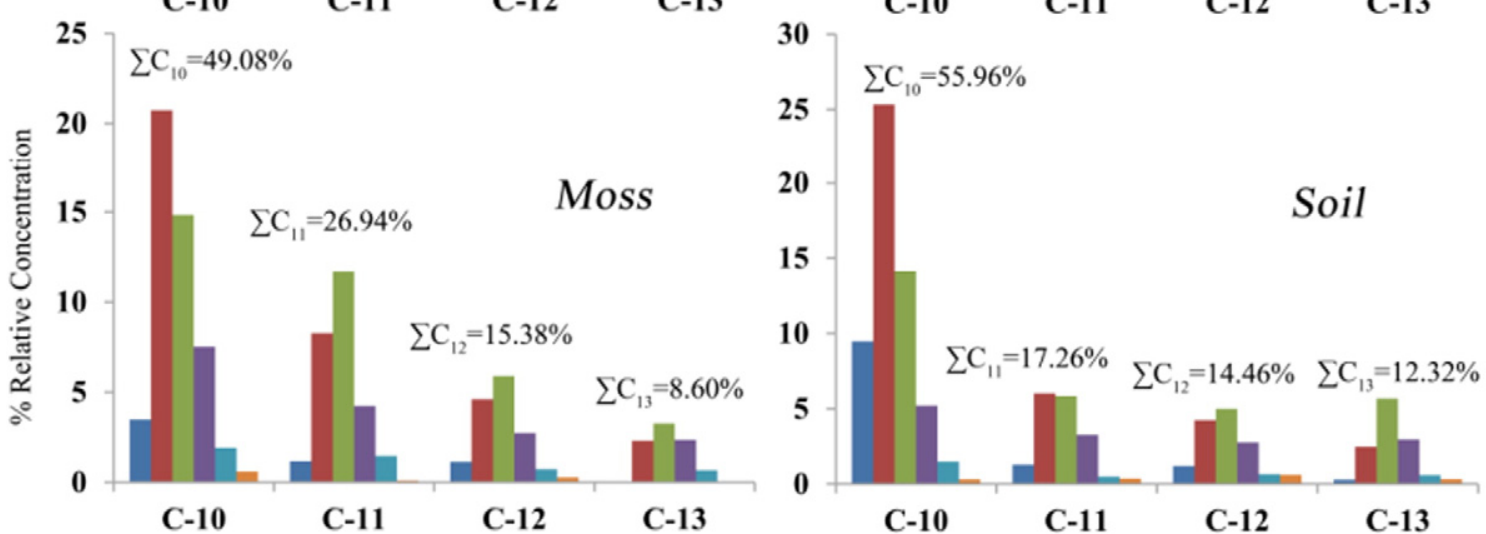

Fig. 2. Patterns of the mean percentages of the SCCP congener groups in six different matrices from Antarctica. 


\subsection{SCCP congener profiles}

The SCCP congeners with 10 carbon atoms ( $C_{10}$ congeners) were dominant in all species, with proportions that varied between $49.1 \%$ and $69.0 \%$ (mean $=58.7 \%$ ) of the total SCCP contamination and followed by $C_{11}$ congeners ( $22.1 \%$, mean), $C_{12}$ congeners ( $11.1 \%$, mean), and $\mathrm{C}_{13}$ congeners (8.2\%, mean) (Fig. 2). Based on the number of chlorine, the SCCPs with 6 and 7 chlorine numbers $\left(\mathrm{Cl}_{6}\right.$ and $\mathrm{Cl}_{7}$ congeners, accordingly) were the predominant congeners and contributed $39.6 \%$ and $32.7 \%$ to the total SCCP contamination, respectively. The SCCP congener pattern in our study was similar to that found in Arctic biota samples for which the congeners with shorter carbon chains $\left(C_{10}\right.$ congeners) and a lower degree of chlorination are also predominant (Tomy et al., 2000). However, the pattern of the SCCP congeners in this study was different from those in urbanized and industrial regions, which are dominated by relatively longer carbon chain congeners, such as $C_{11}$ and $C_{12}$ congeners (Ma et al., 2014b; Yuan et al., 2012; Zeng et al., 2011b).

The congener patterns were analysed in the aquatic and terrestrial biota. The Student's $t$-test confirmed that the proportion of $\mathrm{C}_{10}$ congeners was significantly higher in the aquatic biota (53.8\% for Agas (except for site 3), $68.1 \%$ for $\mathrm{Ngas}, 69.0 \%$ for fish and $57.6 \%$ for algae) than that in the terrestrial biota ( $49.1 \%$ for moss) ( $p=0.028$, Supplementary DataResults for statistical analysis R2). This can be explained by the fact that the $C_{10}$ congeners are more hydrophilic than the longer chain congeners (Drouillard et al., 1998b; Feo et al., 2009), which make them easier to concentrate in aquatic organisms.

The proportion of $C_{10}$ congeners was much higher in the Antarctic samples than that reported in previous studies (Fig. 3) (Borgen et al., 2002; Houde et al., 2008; Ma et al., 2014a; Reth et al., 2006; Tomy et al., 2000; Zeng et al., 2011b). The high volatility and water solubility of shorter carbon chain congeners might explain the higher proportion of $\mathrm{C}_{10}$ congeners in Antarctic samples. The volatility of SCCPs decreases with an increase in the carbon chain length (Drouillard et al., 1998a). $\mathrm{C}_{10}$ congeners have high volatility, but they also have low affinity for atmospheric particulates, which combined result in a strong potential for long-range atmospheric transport. Ma et al. (2014c) also found that $C_{10}$ congeners predominated in Antarctic gas-phase air samples. Additionally, oceanic transport influences the transfer and deposition of pollutants at a global scale (Farrington and Takada, 2014; Dachs et al., 2002). Therefore, the $\mathrm{C}_{10}$ congeners of SCCPs, with lower Kow and higher water solubility values than other congeners, are more difficult for sediments to absorb and can migrate easily with ocean currents for long distances (Feo et al., 2009). The different patterns of congener

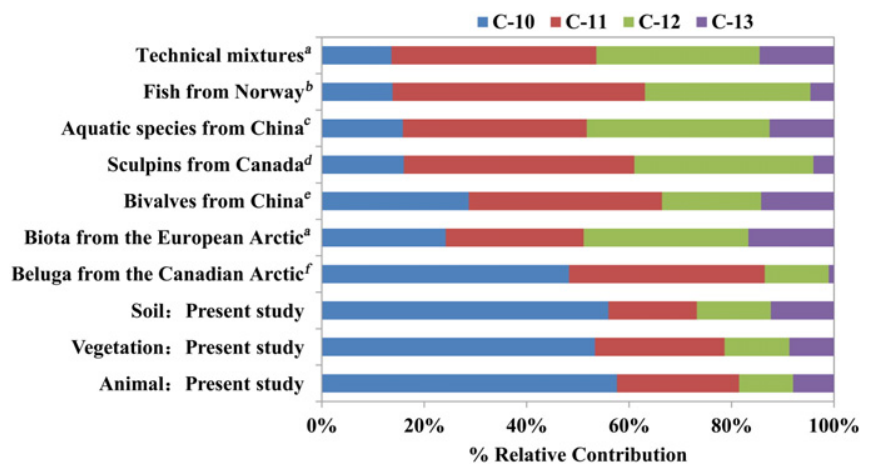

Fig. 3. Comparison of the $C_{10}, C_{11}, C_{12}$ and $C_{13}$ congener group patterns in matrices from Antarctica with those of other studies from different sample areas and technical mixtures (a: Technical mixtures and biota including Arctic char (Salvelinus alpinus), cod (Gadus morhua), little auk (Rissa tridactyla) and kittiwake (Alle alle), Reth et al., 2006; b: Borgen et al., 2002; c: Aquatic species including leather catfish (Silurus meridionalis), common carp (Cyprinus carpio), Chinese softshell turtles (Chinemys reevesii) and java tilapia (Tilapia nilotica), Zeng et al., 2011b; d: Houde et al., 2008; e: Ma et al., 2014a; f: Tomy et al., 2000). groups also indicated that long-range transport might be the primary source of the SCCP burden in Antarctica.

\subsection{Spatial distribution of SCCPS}

Local human activities that include scientific expedition, tourism, and airport service might increase anthropogenic pollution in Antarctica. As shown in Fig. 1, Agas collected at sites 3, 4, and 16 had relatively higher concentrations of SCCPs than those of other sites, with a mean level of $226.5 \mathrm{ng} / \mathrm{g} \mathrm{dw}$. By contrast, the mean concentration of SCCPs was $83.6 \mathrm{ng} / \mathrm{g} \mathrm{dw}$ in Agas collected on the southern part of the Fildes Peninsula (specifically, sites 12,13, and 14), which is far from human activities. The Student's $t$-test found that the concentrations of SCCPs in the Agas samples collected near the research station were significantly higher than those in the Agas samples from the remote sample sites ( $p=3 \times 10^{-6}$, Supplementary Data-R3). Additionally, the patterns of the SCCP congener groups were also different in the Agas collected from the different areas (Fig. S2). In the Agas from the remote sample sites, most of the SCCPs were $C_{10}$ congeners (mean $=60.6 \%$ ), but the pattern of congener groups near the research station (site 3) was similar to that for an industrial area (Ma et al., 2014a), with percentages of the $C_{10}-C_{13}$ groups of $28.2 \%, 36.6 \%, 22.0 \%$ and $13.3 \%$, respectively. The different levels of concentration and patterns of congener groups between those of the research station areas and those of the remote areas indicated that anthropogenic activities were a significant factor in the spatial distribution of SCCPs on the Fildes Peninsula.

The population density is very low on the Fildes Peninsula, and the stations in Antarctica all have efficient waste treatment systems to minimize their influence on the local ecosystems. Wild et al. (2015) studied the influence of scientific stations in Antarctica and found that the levels of PBDEs and perfluoroalkylated substances (PFASs) rapidly decreased within 200-2000 $\mathrm{m}$ of the station areas. Our data also showed a sharp decrease (63.1\%: from station areas to remote areas) in the concentrations of SCCPs in Agas samples, and therefore, the contamination that originated locally in Antarctica likely had little influence on the areas far from human activities. Besides, the congener patterns of SCCPs in the Antarctic samples collected from the remote sites showed a unique feature compared with those of mid- and low-latitude samples and technical mixtures (Fig. 3 ): the proportion of $C_{10}$ congeners was higher. It is not likely that pollution of local origin explains this different SCCP congener pattern. Based on the results, long-range transport is more likely to be the primary source of SCCPs in the Antarctic organisms, particularly for those collected far from the centres of human activity.

\subsection{Bioaccumulation and biomagnification of SCCPS}

Significant correlation between the concentrations of SCCPs and the contents of lipids in biota samples was detected by Pearson correlation analysis ( $p=0.014, N=36$ ). Further regression analysis revealed that the concentrations of SCCPs in biota was linearly dependent on the lipid content (SCCPs concentrations $\mathrm{ng} / \mathrm{g} \mathrm{dw}=(7.8 \pm 3.0) \times$ Lipid contents $\left.+(43.8 \pm 20.2), r^{2}=0.14, p=0.014, N=36\right)$, indicating the great influence of the lipid contents on the SCCPs bioaccumulation because of the hydrophobicity of the pollutants (Fig. S3 and Supplementary Data-R4). Additionally, it was notable that the marine animal species with a higher lipid content had a higher proportion of longer chain congeners than that of the lower lipid-content species (Table S3A and Supplementary Data-R5). According to Feo et al. (2009), the log Kow of SCCP congeners increases with an increase in carbon chain length, which leads to the preferential enrichment of longer carbon chain congeners (higher Kow values) in lipids. In this study, enrichment of the more hydrophobic SCCP congeners also occurred in the species with higher lipid contents (Table S3B).

In aquatic food webs, many POPs can biomagnify or show an increased lipid-normalized concentration from low trophic level species to higher trophic level species (Fisk et al., 2001). In the present study, 
no significant correlation was found between the TL values and the lipid-normalized concentrations of SCCPs in the aquatic samples ( $p=$ $0.57, N=28$; Supplementary Data-R6). However, in previous studies, significant positive correlations between the TL values and the lipidnormalized concentrations of SCCPs were found in the aquatic food chains (Ma et al., 2014b; Zeng et al., 2011b). When considering the influence of a direct predator-prey relationship on the biomagnification of SCCPs, a positive correlation was expected between the predatorprey species in Antarctica. Fortunately, field photos taken during the sampling for this study provided support for the direct predator-prey relationship between the Agas and Ngas species (field photos in Fig. S1: the Ngas is eating the Agas). Moreover, earlier lab-reared studies reported that consumers had stable carbon isotope ratios $\left(\delta^{13} \mathrm{C}\right)$ that were not significantly different from those of their food $\left(\Delta \delta^{13} \mathrm{C}=0.8 \pm 1.1 \%\right.$ 。 $\mathrm{SD})$, whereas the consumers were enriched in ${ }^{15} \mathrm{~N}$ relative to their diet $\left(\Delta \delta^{15} \mathrm{~N}=3.0 \pm 2.6 \%\right.$ o SD) (Jardine et al., 2006). In the current study, the values of $\Delta \delta^{13} \mathrm{C}$ and $\Delta \delta^{15} \mathrm{~N}$ (mean differences for $\delta^{13} \mathrm{C}$ and $\delta^{15} \mathrm{~N}$, respectively) between Agas and Ngas samples were $1.1 \%$ and $2.3 \%$, respectively, which were in the range of the corresponding criteria $\left(\Delta \delta^{13} \mathrm{C}=0.8 \pm 1.1 \%\right.$ o SD; $\Delta \delta^{15} \mathrm{~N}=3.0 \pm 2.6 \%$ o SD, Jardine et al., 2006). These results confirmed the predator-prey relationship between the two species, although other food sources may be consumed (Harper and Peck, 2003). No significant correlation between the TL values and lipid-normalized concentrations of SCCPs in Agas and Ngas samples was detected ( $p=0.17, N=21$, Supplementary Data-R7), which indicated that the complex interplay of physical-chemical and biological processes effect the trophic transfer potential of SCCPs in the Antarctic organisms.

The calculated biomagnification factors (BMFs) of the SCCPs between Ngas and Agas ranged from 0.4 to 3.5, with a mean of 1.9 (Table S4), which is a range consistent with that in the food webs from Lake Ontario and Lake Michigan (0.5-3.6) and indicates that SCCPs could biomagnify between prey and predators (Houde et al., 2008). However, these values were relatively low compared with the trophic magnification factors (TMFs) of other POPs, such as for perfluorooctane sulfonate in a food web from Lake Ontario (TMF = 5.9) (Martin et al., 2004) and for hexabromocyclododecane in a food web from Lake Ontario (TMF = 6.3) (Tomy et al., 2004). The biotransformation half-life of SCCPs (9.8-93.9 d, Table S5) was shorter than that for PCBs (11.2-1647 d), as calculated by the EPI Suite (US EPA, 2012), and indicated that SCCPs are more easily biodegraded than PCBs. Thus, these results indicate that the biomagnification potential of SCCPs through a food chain might be lower than that of other POPs.

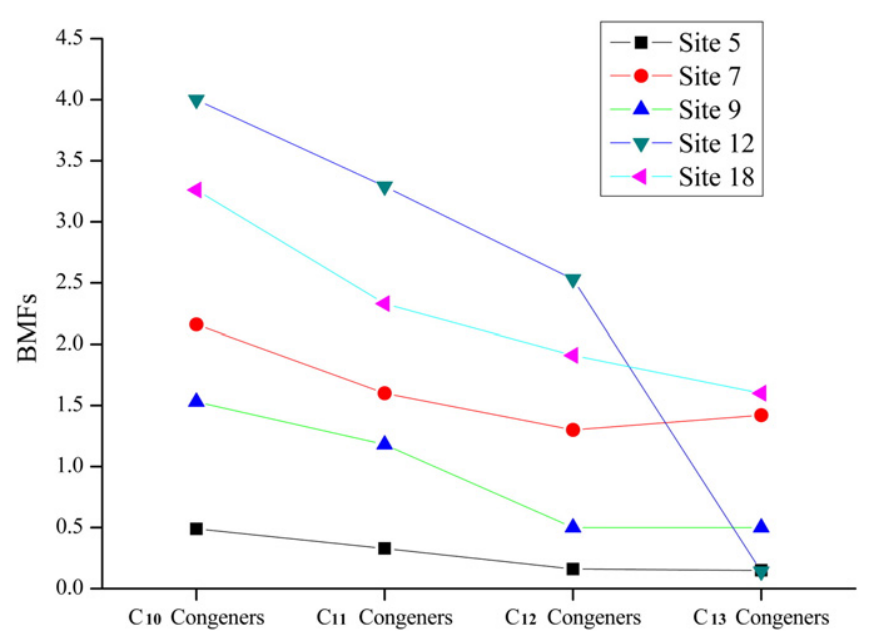

Fig. 4. BMFs for the different SCCP congeners in Antarctic Agas and Ngas species collected from the identical locations.
The BMFs for the individual congener groups $\left(C_{10}-C_{13}\right)$ ranged from 0.1 to 4.0 between the Agas and Ngas species (Fig. 4). The average BMF of the SCCPs decreased from $C_{10}$ to $C_{13}$ congeners, with values of $2.3,1.8$, 1.3 , and 0.8 , respectively. A similar pattern of decreasing BMFs with the increasing carbon chain length of SCCP congeners was observed in a food web from Lake Michigan (Houde et al., 2008). However, in previous laboratory exposure experiments, the BMFs tended to increase with increasing lengths of the carbon chain (Fisk et al., 1998; Fisk et al., 2000). Notably, the biomagnification of shorter chain congeners of SCCPs was higher than that of the longer chain ones in the field study, which might be attributed to the larger molecular sizes of the longer carbon chain congeners, as Mackintosh et al. (2004) found that the concentrations of high molecular-weight phthalate esters declined significantly at higher trophic levels in a marine food web from western Canada.

Lavoie et al. (2013) reported that the biomagnification factors of mercury are the highest ones in cold and low productivity systems through food webs. The average temperature was extremely low and turned out to be approximately $-3{ }^{\circ} \mathrm{C}$ on the Fildes Peninsula at King George Island, Antarctica. Therefore, large BMF values are expected for the SCCPs in the Antarctic biota. Unfortunately, there is no BMF information for SCCPs reported elsewhere for the same predator-prey species in Antarctica, Ngas and Agas. Limited information showed the BMF of SCCPs was 0.9 and 1.2 for the invertebrate-fish food webs in Lake Ontario and Lake Michigan with the temperatures of $16-21{ }^{\circ} \mathrm{C}$ (Houde et al., 2008). A BMF value of 1.6 was observed for different fish species in a cooling-water recipient lake in China with the temperatures above $30{ }^{\circ} \mathrm{C}$ (Zeng et al. 2011b). The BMF of SCCPs was 2.4 for the zooplankton-shrimp-fish food web in Liaodong Bay with an annual average temperature of approximately $10{ }^{\circ} \mathrm{C}$ (Ma et al., 2014b). Clearly, it is impossible to find a clue as to whether or not the biomagnification potential of SCCPs show a temperature-dependent manner due to the species difference. The temperature effect on the biomagnification potential of SCCPs needs further investigation.

\section{Conclusions}

The concentrations of SCCPs in the Antarctic samples of this study were lower than those of the mid- and low-latitude regions. Although human activities affected the local distribution of SCCPs, the longrange transport behaviour of SCCPs was confirmed by the detection of SCCPs in Antarctic remote areas. Additionally, the enrichment of $\mathrm{C}_{10}$ congeners indicated a high potential for the long-range transport of shorter chain congeners. SCCPs were enriched in the species with high lipid contents, and the potential for biomagnification was found between Agas and Ngas species. Most organisms in polar regions are endemics and may be sensitive and vulnerable to the adverse effects of persistent contaminants; therefore, more studies should focus on the potential bioaccumulation and toxicological risks of POPs in polar environments.

\section{Acknowledgements}

This study was jointly supported by the Chinese Academy of Sciences, Grant No. XDB14030500, YSW2013B01, and the National Natural Science Foundation (21277164, 41276195, and 21177146), the Young Scientists Fund of RCEES (RCEES-QN-20130047F), and the State Oceanic Administration, P.R. China (2012GW02002). The authors would also greatly thank Chinese Arctic and Antarctic Ministration for the arrangement during 29th Chinese Antarctic Expedition.

\section{Appendix A. Supplementary data}

Supplementary data to this article can be found online at http://dx. doi.org/10.1016/j.envint.2016.05.005. 


\section{References}

Barber, J.L., Sweetman, A.J., Thomas, G.O., Braekevelt, E., Stern, G.A., Jones, K.C., 2005. Spatial and temporal variability in air concentrations of short-chain $\left(C_{10}-C_{13}\right)$ and medium-chain $\left(\mathrm{C}_{14}-\mathrm{C}_{17}\right)$ chlorinated n-alkanes measured in the U.K. atmosphere. Environ. Sci. Technol. 39, 4407-4415.

Bayen, S., Obbard, J.P., Thomas, G.O., 2006. Chlorinated paraffins: a review of analysis and environmental occurrence. Environ. Int. 32, 915-929.

Borgen, A.R., Schlabach, M., Kallenborn, R., Fjeld, E., 2002. Polychlorinated alkanes in fish from Norwegian freshwater. Sci. World J. 2, 136-140.

Borghini, F., Grimalt, J.O., Sanchez-Hernandez, J.C., Bargagli, R., 2005. Organochlorine pollutants in soils and mosses from Victoria land (Antarctica). Chemosphere 58, 271-278.

Bargagli, R., 2008. Environmental contamination in Antarctic ecosystems. Sci. Total Environ. 400, 212-226.

Campbell, I., McConnell, G., 1980. Chlorinated paraffins and the environment. 1. Environmental occurrence. Environ. Sci. Technol. 14, 1209-1214.

Coelhan, M., 2010. Levels of chlorinated paraffins in water. Clean-Soil, Air, Water 38 452-456.

Dachs, J., Lohmann, R., Ockenden, W.A., Mejanelle, L., Eisenreich, S.J., Jones, K.C., 2002. Oceanic biogeochemical controls on global dynamics of persistent organic pollutants. Environ. Sci. Technol. 36, 4229-4237.

Drouillard, K.G., Hiebert, T., Tran, P., Tomy, G.T., Muir, D.C., Friesen, K.J., 1998a. Estimating the aqueous solubilities of individual chlorinated n-alkanes $\left(C_{10}-C_{12}\right)$ from measurements of chlorinated alkane mixtures. Environ. Toxicol. Chem. 17, 1261-1267.

Drouillard, K.G., Tomy, G.T., Muir, D.C.G., Friesen, K.J., 1998b. Volatility of chlorinated nalkanes $\left(C_{10}-C_{12}\right)$ : vapor pressures and Henry's law constants. Environ. Toxicol. Chem. 17, 1252-1260.

Farrington, J.W., Takada, H., 2014. Persistent organic pollutants (POPs), polycyclic aromatic hydrocarbons (PAHs), and plastics examples of the status, trend, and cycling of organic chemicals of environmental concern in the ocean. Oceanography 27 , 196-213.

Feo, M.L., Eljarrat, E., Barceló, D., 2009. Occurrence, fate and analysis of polychlorinated nalkanes in the environment. Trac-trend. Anal. Chem. 28, 778-791.

Fisk, A.T., Cymbalisty, C.D., Bergman, A., Muir, D.C.G., 1996. Dietary accumulation of $\mathrm{C}_{12^{-}}$ and $\mathrm{C}_{16}$-chlorinated alkanes by juvenile rainbow trout (Oncorhynchus mykiss). Environ. Toxicol. Chem. 15, 1775-1782.

Fisk, A.T., Cymbalisty, C.D., Tomy, G.T., Muir, D.C.G., 1998. Dietary accumulation and depuration of individual $C_{10^{-}}, C_{11^{-}}$and $C_{14^{-}}$polychlorinated alkanes by juvenile rainbow trout (Oncorhynchus mykiss). Aquat. Toxicol. 43, 209-221.

Fisk, A.T., Hobson, K.A., Norstrom, R.J., 2001. Influence of chemical and biological factors on trophic transfer of persistent organic pollutants in the northwater polynya marine food web. Environ. Sci. Technol. 35, 732-738.

Fisk, A.T., Tomy, G.T., Cymbalisty, C.D., Muir, D.C.G., 2000. Dietary accumulation and quantitative structure-activity relationships for depuration and biotransformation of short $\left(C_{10}\right)$, medium $\left(C_{14}\right)$, and long $\left(C_{18}\right)$ carbon-chain polychlorinated alkanes by juvenile rainbow trout (Oncorhynchus mykiss). Environ. Toxicol. Chem. 19, 1508-1516.

Fridén, U.E., McLachlan, M.S., Berger, U., 2011. Chlorinated paraffins in indoor air and dust: concentrations, congener patterns, and human exposure. Environ. Int. 37, 1169-1174.

Gao, Y., Zhang, H.J., Su, F., Tian, Y.Z., Chen, J.P., 2012. Environmental occurrence and distribution of short chain chlorinated paraffins in sediments and soils from the Liaohe River basin, P. R. China. Environ. Sci. Technol. 46, 3771-3778.

Geng, N.B., Zhang, H.J., Zhang, B.Q., Wu, P., Wang, F.D., Yu, Z.K., Chen, J.P., 2015. Effects of short-chain chlorinated paraffins exposure on the viability and metabolism of human hepatoma HepG2 cells. Environ. Sci. Technol. 49, 3076-3083.

Harper, E.M., Peck, L., 2003. Predatory behaviour and metabolic costs in the Antarctic muricid gastropod Trophon longstaffi. Polar Biol. 26, 208-217.

Hodum, P.J., Hobson, K.A., 2000. Trophic relationships among Antarctic fulmarine petrels: insights into dietary overlap and chick provisioning strategies inferred from stableisotope $\left(\delta^{15} \mathrm{~N}\right.$ and $\left.\delta^{13} \mathrm{C}\right)$ analyses. Mar. Ecol. Prog. Ser. 198, 273-281.

Honkanen, J.O., Kukkonen, J.V.K., 2006. Environmental temperature changes uptake rate and bioconcentration factors of bisphenol a in tadpoles of Rana temporaria. Environ. Toxicol. Chem. 25, 2804-2808.

Houde, M., Muir, D.C.G., Tomy, G.T., Whittle, D.M., Teixeira, C., Moore, S., 2008. Bioaccumulation and trophic magnification of short-and medium-chain chlorinated paraffins in food webs from Lake Ontario and Lake Michigan. Environ. Sci. Technol. 42, 3893-3899.

Iozza, S., Muller, C.E., Schmid, P., Bogdal, C., Oehme, M., 2008. Historical profiles of chlorinated paraffins and polychlorinated biphenyls in a dated sediment core from Lake Thun (Switzerland). Environ. Sci. Technol. 42, 1045-1050.

Jardine, T.D., Kidd, K.A., Fisk, A.T., 2006. Applications, considerations, and sources of uncertainty when using stable isotope analysis in ecotoxicology. Environ. Sci. Technol. 40, 7501-7511.

Lavoie, R.A., Jardine, T.D., Chumchal, M.M., Kidd, K.A., Campbell, L.M., 2013. Biomagnification of mercury in aquatic food webs: a worldwide meta-analysis. Environ. Sci. Technol. 47, 13385-13394.

Ma, X.D., Chen, C., Zhang, H.J., Gao, Y., Wang, Z., Yao, Z.W., Chen, J.P., Chen, J.W., 2014a. Congener-specific distribution and bioaccumulation of short-chain chlorinated paraffins in sediments and bivalves of the Bohai Sea, China. Mar. Pollut. Bull. 79, 299-304.

Ma, X.D., Zhang, H.J., Wang, Z., Yao, Z.W., Chen, J.W., Chen, J.P., 2014b. Bioaccumulation and trophic transfer of short chain chlorinated paraffins in a marine food web from Liaodong Bay, North China. Environ. Sci. Technol. 48, 5964-5971.

Ma, X.D., Zhang, H.J., Zhou, H.Q., Na, G.S., Wang, Z., Chen, C., Chen, J.W., Chen, J.P., 2014c. Occurrence and gas/particle partitioning of short-and medium-chain chlorinated paraffins in the atmosphere of Fildes Peninsula of Antarctica. Atmos. Environ. 90, 10-15.

Mackintosh, C.E., Maldonado, J., Jing, H.W., Hoover, N., Chong, A., Ikonomou, M.G., Gobas, F., 2004. Distribution of phthalate esters in a marine aquatic food web: comparison to polychlorinated biphenyls. Environ. Sci. Technol. 38, 2011-2020.

Martin, J.W., Whittle, D.M., Muir, D.C.G., Mabury, S.A., 2004. Perfluoroalkyl contaminants in a food web from Lake Ontario. Environ. Sci. Technol. 38, 5379-5385.

Marvin, C.H., Painter, S., Tomy, G.T., Stern, G.A., Braekevelt, E., Muir, D.C.G., 2003. Spatial and temporal trends in short-chain chlorinated paraffins in Lake Ontario sediments. Environ. Sci. Technol. 37, 4561-4568.

Muijs, B., Jonker, M.T.O., 2009. Temperature-dependent bioaccumulation of polycyclic aromatic hydrocarbons. Environ. Sci. Technol. 43, 4517-4523.

Poremski, H., Wiandt, S., Knacker, T., 2001. Chlorinated paraffins-a further POP to consider? Organohalogen Compd. 52, 397-400.

Reth, M., Ciric, A., Christensen, G.N., Heimstad, E.S., Oehme, M., 2006. Short-and mediumchain chlorinated paraffins in biota from the European Arctic-differences in homologue group patterns. Sci. Total Environ. 367, 252-260.

Strid, A., Bruhn, C., Sverko, E., Svavarsson, J., Tomy, G., Bergman, Å., 2013. Brominated and chlorinated flame retardants in liver of Greenland shark (Somniosus microcephalus). Chemosphere 91 (2), 222-228.

Thomas, G.O., Farrar, D., Braekevelt, E., Stern, G., Kalantzi, O.I., Martin, F.L., Jones, K.C., 2006. Short and medium chain length chlorinated paraffins in UK human milk fat. Environ. Int. 32, 34-40.

Tomy, G.T., Budakowski, W., Halldorson, T., Whittle, D.M., Keir, M.J., Marvin, C., Macinnis, G., Alaee, M., 2004. Biomagnification of $\alpha$ - and $\gamma$ - hexabromocyclododecane isomers in a Lake Ontario food web. Environ. Sci. Technol. 38, 2298-2303.

Tomy, G.T., Muir, D.C.G., Stern, G.A., Westmore, J.B., 2000. Levels of $C_{10}-C_{13}$ polychloro-nalkanes in marine mammals from the Arctic and the St. Lawrence River estuary. Environ. Sci. Technol. 34, 1615-1619.

Tomy, G.T., Stern, G.A., Lockhart, W.L., Muir, D.C.G., 1999. Occurrence of $C_{10}-C_{13}$ polychlorinated n-alkanes in Canadian midlatitude and arctic lake sediments. Environ. Sci. Technol. 33, 2858-2863.

UNEP/POPS/POPRC.3/20, 2008. Decision POPRC-3/8: short-chained chlorinated paraffins. http://chm.pops.int/TheConvention/POPsReviewCommittee/ POPRCRecommendations/tabid/243/ctl/Download/mid/10483/Default.aspx?id= 25\&ObjID $=5557$.

UNEP/POPS/POPRC.8/6, 2012. Revised draft risk profile at POPRC8: short-chained chlorinated paraffins. http://chm.pops.int/TheConvention/POPsReviewCommittee POPRCRecommendations/tabid/243/ctl/Download/mid/10483/Default.aspx?id= $85 \&$ ObjID $=14530$

US EPA, 2012. Estimation Programs Interface Suite ${ }^{\mathrm{TM}}$ for Microsoft ${ }^{\circledR}$ Windows, v 4.11 United States Environmental Protection Agency, Washington, DC, USA.

Vulykh, N., Dutchak, S., Mantseva, E., Shatalov, V., 2007. NEW SUBSTANCES: Model Assessment of Potential for Long-Range Transboundary Atmospheric Transport and Persistence of Short Chain Chlorinated Paraffins (SCCPs). EMEP MSC-E Information Note 5.

Wang, P., Zhang, Q.H., Wang, T., Chen, W.H., Ren, D.W., Li, Y.M., Jiang, G.B., 2012. PCBs and PBDEs in environmental samples from King George Island and Ardley Island, Antarctica. RSC Adv. 2, 1350-1355.

Wang, T., Wang, Y.W., Jiang, G.B., 2013. On the environmental health effects and socioeconomic considerations of the potential listing of short-chain chlorinated paraffins into the Stockholm convention on persistent organic pollutants. Environ. Sci. Technol. 47, 11924-11925.

Wang, T., Yu, J.C., Han, S.L., Wang, Y.W., Jiang, G.B., 2015. Levels of short chain chlorinated paraffins in pine needles and bark and their vegetation-air partitioning in urban areas. Environ. Pollut. 196, 309-312.

Wang, Y.W., Wang, T., Li, A., Fu, J.J., Wang, P., Zhang, Q.H., Jiang, G.B., 2008. Selection of bioindicators of polybrominated diphenyl ethers, polychlorinated biphenyls, and organochlorine pesticides in mollusks in the Chinese Bohai Sea. Environ. Sci. Technol. 42, 7159-7165.

Wania, F., 2003. Assessing the potential of persistent organic chemicals for long-range transport and accumulation in polar regions. Environ. Sci. Technol. 37, 1344-1351.

Wania, F., Mackay, D., 1993. Global fractionation and cold condensation of low volatility organochlorine compounds in polar regions. Ambio 10-18.

Wania, F., Mackay, D., 1996. Peer reviewed: tracking the distribution of persistent organic pollutants. Environ. Sci. Technol. 30, 390A-396A.

Wild, S., McLagan, D., Schlabach, M., Bossi, R., Hawker, D., Cropp, R., King, C.K., Stark, J.S. Mondon, J., Nash, S.B., 2015. An Antarctic research station as a source of brominated and perfluorinated persistent organic pollutants to the local environment. Environ. Sci. Technol. 49, 103-112.

Yuan, B., Wang, T., Zhu, N.L., Zhang, K.G., Zeng, L.X., Fu, J.J., Wang, Y.W., Jiang, G.B., 2012. Short chain chlorinated paraffins in mollusks from coastal waters in the Chinese Bohai Sea. Environ. Sci. Technol. 46, 6489-6496.

Zeng, L.X., Lam, J.C.W., Wang, Y.W., Jiang, G.B., Lam, P.K.S., 2015. Temporal trends and pattern changes of short- and medium-chain chlorinated paraffins in marine mammals from the South China Sea over the past decade. Environ. Sci. Technol. 49, 11348-11355.

Zeng, L.X., Wang, T., Han, W.Y., Yuan, B., Liu, Q., Wang, Y.W., Jiang, G.B., 2011a. Spatial and vertical distribution of short chain chlorinated paraffins in soils from wastewater irrigated farmlands. Environ. Sci. Technol. 45, 2100-2106.

Zeng, L.X., Wang, T., Wang, P., Liu, Q., Han, S.L., Yuan, B., Zhu, N.L., Wang, Y.W., Jiang, G.B. 2011b. Distribution and trophic transfer of short-chain chlorinated paraffins in an aquatic ecosystem receiving effluents from a sewage treatment plant. Environ. Sci. Technol. 45, 5529-5535.

Zhu, N.L., Li, A., Wang, T., Wang, P., Qu, G.B., Ruan, T., Fu, J.J., Yuan, B., Zeng, L.X., Wang, Y.W., Jiang, G.B., 2012. Tris(2,3-dibromopropyl) isocyanurate, hexabromocyclododecanes, and polybrominated diphenyl ethers in mollusks from Chinese Bohai Sea. Environ. Sci. Technol. 46, 7174-7181. 